Session_2560

\title{
Improving Students Retention by Engaging Them in Real Life Experiences
}

\author{
Hazem Said \\ Department of Mathematics, Physics and Computing Technology, \\ University of Cincinnati
}

Introduction

Engaging engineering technology students in real life experiences has a positive impact on retention rate. The Center for Information Technology and Community Development (CITCD) at the University of Cincinnati initiated the IT-Students-Work project (ITSW) as part of its plan to establish strong relationship between students in the Information Technology program and the community. ${ }^{1}$

The idea of the ITSW came after the realization of two issues. The first issue is that Information Technology (IT) solutions have a great impact on the operation of non-profit and educational organizations the same way it impacts commercial businesses. However, generally, non-profit and educational organizations do not have enough budgets to develop the IT solutions they need. The second issue is that undergraduate students who are pursuing a degree in Information Technology have skills that allow them to develop much of the solutions that non-profit or educational organizations will need. The ITSW was then established to bring these two issues together.

The ITSW project is an original project that builds on the accumulated experience of cooperative education, service learning and experiential learning. It is an established fact that students are more prepared when they acquire experiences related to the knowledge areas of their degree programs.

Format of the IT-Students-Work Project (ITSW)

There are three goals for the ITSW project. The first is to provide an opportunity for nonprofit and educational organizations and even small business to have Information Technology solutions to help their operation. The second is to provide a practical life experience for undergraduate students in which they apply what they learn in the classroom. The third is to empower a sense of responsibility towards the community in undergraduate students.

There are two ways students can participate in ITSW. The first is to fulfill their cooperative education requirement. Through ITSW, projects are made available that require full time employment and students are hired as full time coop employee for one or two quarters. The second way students can participate in ITSW is through part-time 
employment. Most of the undergraduate students work part-time during school for 10-20 hours per week. Through ITSW, projects are made available where students can work part-time. ITSW simulates consulting firm that receives projects from different clients and hire students to develop and implement these projects. The difference between ITSW and a consulting firm is that ITSW does not seek profit. In addition, ITSW focuses on students' learning. ITSW is managed by faculty members who volunteer for this work and there is educational objective behind ITSW to link classroom experience and the learning objectives to real life experiences.

Through ITSW, students are engaged in the different phases of the project life cycle, from the analysis, design, implementation, and deployment and testing. They attend conferences with the client to discuss the need and the solution as well as the technology used. Student will then develop a prototype and present it to the client. Because of the nature of non-profit organizations, students are the ones who deploy the solution and in many cases, train the employees on how to maintain it.

In addition to the technical experience that students gain through participation in the project, there learn a great deal about communication. Oral and written communication is experienced through communication with the client at the different phases of the project as well as with their supervisor (the faculty member). In many cases, students were required to present a prototype to representatives from the client and to train client's employee on using and maintaining the solution. Students also learn about time management, deadlines and priorities throughout the project. In some cases, students worked in teams and collaborated with other professional developers.

A faculty member acts as a supervisor. His responsibility would be to identify the problem and receive projects from the non-profit organization. He then directs the students through the analysis, design and development of the solution.

The project started in the summer of 2002 and since then has helped three non-profit organizations, one elementary school and three units within the University of Cincinnati. ${ }^{2}$ The project employed seven students as full time, each for two quarters. Three students were hired as part-time.

\section{Finances of ITSW}

The funding for ITSW is provided by the organization who requested the work. The expenses of ITSW are mainly the students' time. CITCD provided the space, the hardware and the software needed. A core concept of ITSW is that students must be paid for their time and organizations who receive the product must contribute to the development of the product. The presence of this financial element in the project ensures seriousness and commitment of both the organization and the student. It is also a requirement to make ITSW a real life experience.

Although organizations who hire ITSW contribute partially or fully to the expenses of the project, this cost is by far much less than the commercial cost of the project. Thus, the benefit for these organizations is that they receive a quality product in a much less cost. In addition, this collaboration between the ITSW and the organization provides strong foundation for grant proposals since the ultimate goal of ITSW is to enhance students' learning experience and to empower community organizations. 


\section{Examples of ITSW Projects}

Students worked on different projects in ITSW in the different competency areas of IT such as web development, digital media, database and software development. Details of these projects are available on the ITSW web site ${ }^{2}$.

One student developed a manual on how to update your web site using Front page. The student then delivered a 3 hours workshop to employees on how to update the web site. The manual was later used by other students as well.

Impact of the ITSW

This impact of ITSW is mainly long term and may not be fully realized before several years of successful implementation. ITSW will positively impact students' retention because it:
* Enhances students' learning experience
* Relate college activities to real-life projects.
* Relate students to their communities.

However, there is a short term impact that can be realized and that measures if there is a need for such project or not. To measure that short term impact, a survey was given to students who participated in ITSW through full-time or part-time employment.

The survey collected information about students' gender, academic status, type and length of employment, the projects they worked on and the impact of their experience with ITSW. All the 10 students who participated in ITSW responded to the survey.

Thirty percent of the students who participated in the project were female. This ration is higher than the ratio of female students in the program. This suggests that female students are attracted to programs like ITSW and that these programs may be a factor in attracting and retaining female students.

Students work experience in ITSW is different from regular coop or part-time employment in that it gives them opportunity to participate in the full project development life cycle. Students spend the majority of their time on implementation. Figure 1 shows the distribution of the average students time spent on the different stages of project life cycle. Forty percent of students' time was spent on the implementation while $15 \%$ percent was spent on analysis and testing. Twenty five percent of their time was design and $5 \%$ on training. 


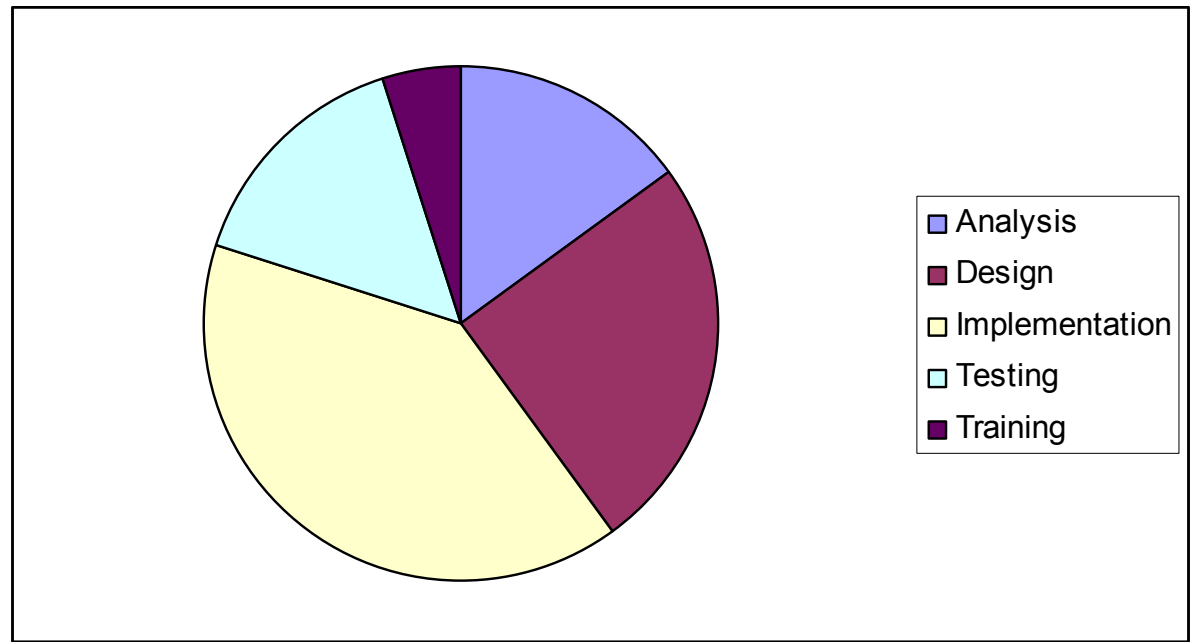

Figure 1: Average students' time spent on the different stages of project life cycle

Several students emphasized that the benefited from working with a faculty member as their supervisor. This helped them know the faculty member more and to understand how the college system work. In addition they mentioned that the faculty member knew what they were capable of doing so their assignment were at their level and yet was meaningful and necessary. Some of the students' quotes were:

"You are also my advisor so it was good to get to know you..."

“...He was also very conscious of my career aspirations and experience needs. He provided me with projects that would be most favorable to me. These projects were always things that were meaningful and necessary, but they were also projects that fit my knowledge-level and capabilities perfectly.."

".. He knew what I was capable of and gave me time to learn new things/concepts..”

“..It helped me realize that I could use the skills learned in class to create a final product."

“.. We have freedom to learn, experiment and create.."

“.. By having a faculty member as my supervisor, they knew what I was capable of and what skills I possessed. They were able to give me assignments that would be challenging but also reasonable.."

“..He knows what I am capable of doing and expects nothing less from me" 


\section{Conclusion}

In conclusion, ITSW provided the students with a unique learning opportunity. Students experience the full project development life-cycle and engaged in client meetings, training and tutoring.

\section{References}

1. Said, Hazem, "Information Technology Education and Community Development: A Partnership", Proceedings of the 2002 Conference for Information Technology Curriculum, Rochester, NY

2. The IT-Students-Work Project, http://citcd.uc.edu/itsw

3. Azadivar, Farhad and Tucker, Jeff, “Engineering Learning Center; Description, results and lessons learned", Proceedings of the $30^{\text {th }}$ Annual Frontiers in Education Conference, Kansan, MO (2000)

\section{HAZEM SAID}

Dr. Hazem Said is an Assistant Professor of Information Technology. He is the founding director of the Center for Information Technology and Community Development. His research deals with curriculum development and bridging the gap between the university and the community. He also works on students' retention and success in college. Dr. Said can be reached at 513-556-4874, hazem.said@uc.edu. 